\title{
Repeat Victimisation, Retraumatisation and Victim Vulnerability
}

\author{
Nicola Graham-Kevan*, Matthew Brooks, VJ Willan, Michelle Lowe, Phaedra Robinson, Roxanne \\ Khan, Rachel Stokes, May Irving, Marta Karwacka and Joanne Bryce
}

School of Psychology, University of Central Lancashire, UK

\begin{abstract}
This study explores the contribution that traumatic experiences and psychological post-traumatic stress symptoms make to predicting subsequent revictimisation in a sample of violent crime victims. In addition, the timing of first trauma exposure was also explored. Fifty-four adult victims (27 male and 27 female) of police recorded violent crime were interviewed and their traumatic exposure history, trauma symptomology, age at first trauma exposure as well as psychological and psychosocial functioning were assessed. These victims were followed longitudinally and subsequent revictimisation between six and twelve months post index victimisation measured. A greater number of types of trauma exposure was related lower emotional stability, higher trauma symptomology and revictimisation. Those victims with childhood traumatic exposure reported more trauma symptomology exposure than those without prior exposure. The implications for law enforcement and victim services are discussed.
\end{abstract}

Keywords: Crime, victims, violence, psychological trauma, post traumatic press.

Interest in revictimisation (revictimisation refers here to any subsequent victimisation after the recorded index violent victimisation) has been increasing over the past decade (Farrell, 2005) and so the factors that help to explain this phenomena are an important area to research (Davis, Maxwell, \& Taylor, 2006). There appears to be risk heterogeneity for repeat victimisation, for example Weisel (2005) found that over a 25 -year period $11 \%$ of victims of assault sustained $25 \%$ of all assaults. Indeed, personal crimes such as violence have been suggested to have the highest rates of any offences for repeat victimisation (Farrell, 2005; Kessler, Berglund, Demler, Merikangas, Jin \& Walters, 2005; Pease, 1998). Understanding the factors that increase vulnerability to repeated victimisation in high risk groups such as violent crime victims therefore has the potential to significantly reduce crime rates (Farrell, 2005; Pease, 1998).

One of the mechanisms by which violent crime victims' vulnerability is likely to be increased is via the psychologically negative impact such events have on the victim. The sudden, unanticipated nature of violent criminal incidents can act as a catalyst for a wide range of trauma symptoms. A traumatic event is said to occur during "exposure to actual or threatened death, serious injury or sexual violence" (American Psychiatric Association, 2013, p. 271), which is "likely to result in pervasive distress to almost anyone" (World Health Organisation, 2010). Many violent incidents, such as domestic violence, would fit these criteria. Therefore it may be that trauma symptomology following a violent incident is one of the mechanisms by which the risk

*Address correspondence to this author at the School of Psychology, University of Central Lancashire, Preston, Lancashire, UK. PR1 2HE;

Tel: 441772 893726; Fax: 441772892925

E-mail: ngraham-kevan@uclan.ac.uk of subsequent victimisation increases. This could be through maladaptive coping (Fortier, DiLillo, Messman-Moore, Peugh, DeNardi \& Gaffey, 2009), such as substance use (Dumais, De Benedictis, Joyal, Allaire, Lessage \& Côte, 2013; Hassel, Nordfjærn \& Hagen, 2013), hypervigilance leading to aggression (Naragon-Gainey, Hoerster, Malte \& Jakupcak, 2012; Roberton, Daffern \& Bucks, 2012) or avoidance leading to failures to detect risky situations (Batten, Follette \& Aban, 2002; DePrince, 2005; Hulette, Kaehler \& Freyd, 2011).

According to classifications of mental disorders (American Psychiatric Association, 2013), trauma symptoms are generally clustered into four areas: avoidance behaviours, intrusions (nightmares/flashbacks), negative moods/states or thinking styles and hyperarousal (feeling on guard or easily startled). The occurrence of post-trauma symptomology differs between victims but prevalence can be as high as 80 per cent in some violent crime cohorts (e.g. domestic violence victims: Walsh, Danielson, McCauley, Saunders, Kipatrick \& Resnick, 2012; Dutton, Green, Kaltman, Roesch, Zeffiro \& Krause, 2006). The adverse emotional, psychological and social consequences of crime continue for weeks, months or even years post-victimisation (Halligan, Michael, Clark \& Ehlers, 2003) and may impact upon mental health (Finklehor, Turner, Hamby \& Ormrod, 2011), interpersonal relationships (Unger \& de Luca, 2014) and difficulties with employment, finance and social isolation (Davidson, Devaney \& Spratt, 2010; Sansone, Leung \& Wiederman, 2012). Therefore, how a victim copes with a violent incident may be crucial in predicting the severity of trauma symptomology (Halligan et al., 2003) and the risk of subsequent victimisation, which will increase the current limited understanding of risk heterogeneity (Davidson et al., 
2010; Kelly, Merrill, Shumway, Alvidrez \& Boccellari, 2010).

As victimisation patterns suggest that a small proportion of the population is most vulnerable to repeated incidents (Farrell \& Pease, 1993; Farrell, Tseloni \& Pease, 2005; Tilley \& Laycock, 2002) and those who have experienced one trauma are at heightened risk of additional subsequent traumatic incidents (Zayfert, 2012), factors that may help flag high risk victims are important to guide the design and allocation of the limited resources available to aid crime victims' recovery. Repeated traumatisation, as compared to single incidents, are associated individual level variables such as personality (Outlaw, Ruback \& Britt, 2002) and with poorer psychological outcomes for victims (e.g. Follette, Polusny, Bechtle \& Naugle, 1996; Sullivan et al., 2009; Winkel, Blaauw, Sheridan \& Baldry, 2003). Interpersonal acts such as domestic violence are characterised by frequent acts of multiple types of violence (Mezey, Bacchus, Bewley \& White, 2005), certainly at least partly explained by the frequently ongoing contact between the parties (Cohen \& Felson, 1979; Farrell, 1995), and so it is important to control for domestic violence in any analysis. Likewise those who are subject to more than one type of trauma or incidents perpetrated by different people are also likely to fair less well (Follette, et al., 1996; Cabrera, Hoge, Bliese, Castro \& Messer, 2007). This may be particularly the case when first traumatic exposure occurred in childhood (Finkelhor et al., 2011; Perkins \& Graham-Bermann, 2012; Stimmel, Cruise, Ford \& Weiss, 2014) where difficulties across attachment and relationships, emotional responses, dissociation, externalising or internalising behaviour, cognitions, selfconcept and sense of purpose (The National Child Traumatic Stress Network, 2015). This is also supported by research on revictimisation that has found that adult victims of violence have risk factors preceding the first police recorded violent victimisation (Faergemann, Lauritsen, Brink \& Mortensen, 2010).

Studies suggest there may be enduring effects of early adverse life experience upon later responses to threat. Recent psychological understanding of the neurology and psychology of early trauma support this in that trauma can have a pervasive negative effect on psychological functioning particularly emotional stability (Van der Kolk, 2014). Emotional instability may result in unmanageable distress that creates a spiral of self-amplifying arousal (Dutton, 2002), in what Meloy (1992) terms a catathymic crisis, where the individual becomes overwhelmed by "a seemingly unsolvable state of chronic, aversive emotional tension, viewed as inescapable" (p. 408). Effective emotional regulation is associated with a range of psychological and social benefits (John \& Gross, 2004), whereas poor emotional regulation has many adverse outcomes in terms of psychopathology, psychosocial functioning and health (Aldao, Nolen-Hoeksema, \& Schweizer, 2010; Bradley, 2000).

Interpersonally, a significant factor in recovery following a traumatic incident is the presence of a social support network. Findings are consistent in the view that greater perceived social support is associated with a decreased likelihood of trauma symptoms (Brewin, Andrews \&
Valentine, 2000; Dyb et al., 2014; Evans, Steel, Watkins \& DiLillo, 2014). One of the mechanisms by which social support helps is by mitigating distress via the use of increased adaptive, problem-solving strategies by the victim (Green \& Pomeroy, 2007).

Whilst an initial adverse reaction is expected in the aftermath of a traumatic event, the duration of trauma symptoms is often an indicator of severity. Symptoms meet diagnostic criteria for acute stress disorder if they are present between a minimum of three days and a maximum of four weeks after an event (American Psychiatric Association, 2013). For symptoms that persist beyond four weeks, a diagnosis of post-traumatic stress disorder (PTSD) is considered. This is characterised by frequent intrusive thoughts, avoidance behaviours and hypervigilance, to the extent that they impair everyday psychological functioning (American Psychiatric Association, 2013). While the characteristic effects of trauma in victim samples have been documented, knowledge is presently limited with respect to how this interacts to increase victim vulnerability and potential future revictimisation risk.

The current study seeks to explore association between traumatic experiences occurring prior to violent crime victimisation, trauma symptomology and subsequent revictimisation risk. Additionally, the impact of childhood versus adulthood first traumatic exposure will be explored in relation to victim psychological and psychosocial functioning. The first phase of the study involves interview data from 54 participants who had been the victim of a violent crime as well as psychometric data from measures of social support, coping, personality, trauma exposure, and trauma symptomology. The second phase involved recording subsequent police recorded crime victimisation as well as a follow-up interview with a subsample (17 participants) of the phase one interviewees. It was predicted that the range of trauma exposure (sequential trauma) and trauma symptomology would predict subsequent criminal victimisation. It was also predicted that those whose first traumatic exposure occurred in childhood would report less social support, use less adaptive coping, have lower emotional stability, conscientiousness, openness to experience, and have higher trauma symptoms that those whose had not experienced childhood trauma.

\section{METHOD}

\section{Participants}

The participants consisted of 54 victims (27 male, 27 female) of violent crime, who were recruited from a larger concurrent study into repeat victimisation in the city of Preston, UK (Lowe et al., under review). Eight participants had a history of domestic abuse. Nine participants (not necessarily those with history of domestic abuse) had a current index domestic abuse victimisation. Only three of those with current domestic abuse victimisation had history of such abuse. Data were collected from the police database (PD) held at Lancashire Constabulary, Victim Support (VS) and Preston Domestic Violence Services (PDVS) between April 2013 and September $2013(n=869$ total adult violent crime cases). For this particular study, the majority of participants $(85 \%)$ were sampled from the PD, with smaller 
proportions from the VS (9.3\%) and PDVS (5.6\%) databases. One hundred and sixty participants initially agreed to participate; however, 69 could not be re-contacted for interview, 19 cancelled appointments, 26 did not attend previously arranged appointments and 12 later actively declined. Therefore, 54 victims completed this phase of the study, representing a response rate of $33.8 \%$ at phase 1 . Revictimisation data (phase 2) were collated for the yearlong period after phase 1 in October 2014 for the 54 participants.

The victims in the sample ranged from 18 to 67 years old $(M=37.19$ years, $S D=13.67)$ and the majority $(80.4 \%)$ were of White ethnicity, followed Asian (10.9\%), Mixed (4.3\%), Black (2.2\%) and Other (2.2\%). The largest proportion of participants were single $(43.4 \%)$ and identified as heterosexual $(98.1 \%)$. Almost two-thirds $(64.9 \%)$ of the sample were victims of assault (including police recorded domestic violence), with smaller numbers who were victims of public fear, alarm or distress $(N=6)$, aggravated harassment $(N=4)$, robbery $(N=3)$, wounding $(N=1)$, and sexual assault $(N=1)$. Seventeen of the original participants returned six months later to complete the qualitative study in phase two.

\section{Materials}

The following scales were administered in phase 1 . The 2-Way Social Support Scale (2-Way SSS; ShakespeareFinch \& Obst, 2011). The 2-Way SSS is a 21-item measure of giving and receiving emotional and instrumental social support on a scale from 0 (not at all) to 5 (always). There are four subscales of receiving emotional support (RES), giving emotional support (GES), receiving instrumental support (RIS) and giving instrumental support (GIS) which respondents are asked to rate. Example items include, 'There is someone in my life I can get emotional support from' (RES) and 'There is someone who will help my fulfil my responsibilities when I am unable' (RIS). Higher scores are reflective of greater giving or receiving emotional and instrumental support. The maximum scores for the subscales are as follows: RES - 35, GES - 25, RIS - 20 and GIS - 25. The subscales demonstrated high internal consistency (ranging from .81 to .92) in two community samples (Shakespeare-Finch \& Obst, 2011). In this study, the 2-Way SSS demonstrated high reliability for the overall measure ( $\alpha$ $=.94$ ) and its subscales (ranging from .78 to .95).

Brief COPE (Carver, 1997). The Brief COPE is a 28 -item measure assessing coping styles on a scale from 1 (I haven't been doing this at all) to 4 (I've been doing this a lot). There is no overall score for the measure, however there are 14 subscales consisting of two items each, exploring styles such as acceptance, behavioural disengagement, denial, positive reframing, self-blame and substance use. Respondents are invited to rate which coping styles they employ and example items include, 'I've been thinking hard about what steps to take' (active coping) and 'I've been refusing to believe that it has happened' (denial). Endorsement of a particular coping style is reflected by a higher score for that particular scale. The maximum score for each subscale is 8 . It has demonstrated good internal reliability in a community sample (Carver, 1997). Internal consistency for the Brief
COPE was high overall $(\alpha=.87)$; the Cronbach's alpha for its subscales ranged from .35 to .96 .

Ten-Item Personality Inventory (TIPI; Gosling, Rentfrow \& Swann Jr., 2003). The TIPI is a brief measure of the 'Big Five' personality traits of agreeableness, conscientiousness, emotional stability, extroversion and openness to experiences. It consists of ten items ranging from 1 (disagree strongly) to 7 (agree strongly), such as 'I see myself as extroverted, enthusiastic' (extroversion) and 'conventional, uncreative' (openness to experience). The highest score for each subscale is 14 , which reflects greater endorsement of a particular personality trait. The measure demonstrates acceptable test-retest reliability and convergent validity with other measures of the 'Big Five' traits (Gosling et al., 2003). The scale demonstrated acceptable internal reliability overall $(\alpha=.50)$ and for its five subscales (ranging from .13 to .76).

Connor-Davidson Resilience Scale-2 (CD-RISC 2; Vaishnavi, Connor \& Davidson, 2007). The CD-RISC 2 is a two-item measure of resiliency. The items 'I tend to bounce back after illness or hardship' and ' $I$ am able to adapt to changes in my life' are rated on a seven-point scale ranging from strongly disagree to strongly agree. The maximum attainable score is 14 , with higher scores reflecting greater resilience. The CD-RISC 2 demonstrates similar convergent validity, divergent validity and test-retest reliability similar to that of the larger version both in clinical and general population samples (Vaishnavi et al., 2007). Internal reliability for the measure was good $(\alpha=.77)$.

Impact of Events Scale - Revised (IES-R; Weiss \& Marmar, 1997). The IES-R is a self-report screening measure of PTSD symptoms. It consists of 22 items rated on a fivepoint scale from 0 (not at all) to 4 (extremely), with items along three dimensions of avoidance, intrusion and hyperarousal. Mean scores are calculated for the individual subscales, of which the maximum score is four, and an overall score of 88 . Higher scores indicate greater subjective distress, where scores exceeding the cut-off of 33 indicate probable PTSD. The IES-R displayed excellent internal consistency overall $(\alpha=.95)$ and for its three subscales (ranging from .82 to .94 ).

Brief Betrayal Trauma Survey (BTTS; Goldberg \& Freyd, 2006). The BTTS is a measure of historical betrayal trauma. The eight questions in this version assessed a variety of interpersonal (e.g. 'Have you ever been physically attacked?') and non-interpersonal (e.g. 'Have you ever experienced a major auto, train, plane or industrial accident?') traumas. Participants are also asked to record if the trauma occurred as a child and/or adult. Responses were summed to create a sequential trauma (Layne, Warren, Saltzman, Fulton, Steinberg \& Pynoos, 2006) score which ranged from 0 to 8 . Participants were also coded as to whether they had no prior trauma, only adult trauma or child trauma. The scale was validated in a large community sample (Goldberg \& Freyd, 2006).

Assessing Vulnerable Victims Interview Schedule (AVV Interview Schedule). The AVV Interview Schedule was developed for the second phase of the current study. Of 
relevance to the current study participants were asked to describe 'How you are feeling now within yourself?'

\section{Procedure}

The PD and VS databases were accessed to identify and collate victim demographics, vulnerability factors, crime characteristics, previous offending and victimisation history and support types for all violent crimes recorded for victims aged 16 and above between April and September 2013. Following the identification of variables, data were inputted and collated into a single statistical database (SPSS version 22). A final database of 869 cases was produced where sufficient data could be utilised for further analysis and the index victimisation had occurred in either of the two defined postcodes (PR1 or PR2).

Participants from the combined victim database were invited by phone to participate in the research. They were informed as to the nature of the research and offered the opportunity to complete the questionnaires at a number of locations for their convenience (e.g. the local police station, the offices of VS or PDVS, or the University of Central Lancashire), with a choice of female or male researcher. It was stressed that their participation in this study was entirely separate to the services provided to them by the police or victim services. Participants could withdraw at any time until they returned their completed questionnaires and left the researcher. There were limits to confidentiality such that if any sensitive disclosures were made that indicated a risk of harm to the participant or others, the appropriate professionals would be notified. At the end of the questionnaires, the sample indicated whether or not they wished to participate in the second, qualitative phase of the study; 44 out of the 54 participants recorded their willingness to take part.

Six months later, participants were re-contacted to establish if they wished to continue their involvement in the study. Of the 44 participants who initially agreed to take part, five subsequently declined and seven were unobtainable. Eight appointments could not be finalised due to the participant's other commitments and a further seven appointments were arranged with participants who did not attend. Accordingly, 17 participants took part in the followup interview, which was held at one of the locations previously used in the first phase. The duration of interviews ranged from 30 minutes to three hours and these were audiorecorded for transcription purposes with the participant's consent. All identifying information (such as names and addresses) was removed in the transcriptions and stored along with the first phase data in a lockable filing cabinet.

Qualitative data were analysed using inductive thematic analysis procedures according to the methodology outlined by Braun and Clarke (2006), which allows experiences to be grouped together according to similar attributes and eventually overall themes. The interview transcripts were read and re-read by the research team to ensure comprehension, with potential themes discussed and agreed by the authors. This involved some of the initial themes being re-classified into broader themes with subthemes.

\section{RESULTS}

Pearson's $\chi^{2}$-tests were used for bivariate analyses of categorical variables, and Pearson's correlations were applied for continuous variables. Hierarchical multiple regression was used to explore predictors of revictimisation at phase 2. Analysis of variance was used to explore mean differences.

Prior to conducting the analysis to explore the research questions the study sample was compared to those participants who chose not to take part (i.e. those who either declined, cancelled the interview or did not attend the scheduled interview), those where contact was lost, and those that attended the interview. There were no significant differences in these three groups in terms of participant gender $\left(\chi^{2}=2(.365), p=.833\right)$, index victimisation type $\left(\chi^{2}=\right.$ $8(4.893), p=.769)$, victim-perpetrator relationship $\left(\chi^{2}=\right.$ 8(8.169), $p=.417)$, whether the index victimisation was domestic abuse $\left(\chi^{2}=2(1.547), p=.461\right)$, whether the victim had a history of police recorded domestic abuse $\left(\chi^{2}=\right.$ $4(5.753), p=.218)$, the area the crime was committed $\left(\chi^{2}=\right.$ 2(.500), $\mathrm{p}=.779)$, or the area of the victim's residence $\left(\chi^{2}=\right.$ $16(15.361), \mathrm{p}=.498)$, or victim ethnicity $\left(\chi^{2}=8(9.674), p=\right.$

Table 1. Prevalence of types of trauma exposure for men $(N=27)$ and women $(N=27)$.

\begin{tabular}{|l|c|c|c|c|}
\hline & \multicolumn{2}{|c|}{ Men } & \multicolumn{2}{c|}{ Women } \\
\hline & No & Yes & No & 0 \\
\hline \hline T1 Natural Disaster & 21 & $6^{*}$ & 25 & 4 \\
\hline T2 Man-made Disaster & 18 & 8 & 21 & 14 \\
\hline T3 Witness Severe Attack & 20 & 7 & 11 & 14 \\
\hline T4 Severely Attacked & 13 & 14 & 11 & $7^{*}$ \\
\hline T5 Sexual Assault & 27 & 0 & 18 & 0 \\
\hline T6 Witness Family Attack & 21 & 6 & 15 & $19^{*}$ \\
\hline T7 Psychological Abuse & 20 & 7 & 6 & 2 \\
\hline T8 Child Death & 26 & 0 & 23 & \\
\hline
\end{tabular}

Note. *denotes significant difference between men and women. 
$.289)$.

Prevalence rates for each type of traumatic experience (throughout the participants' life) measured for males and females are presented in Table 1. There were only three types of trauma that differed significantly between men and women. Men reported having experienced significantly more natural disasters than women $\left(\chi^{2}=1(4.922), p=.027\right)$, while women reported experiencing more sexual assault $\left(\chi^{2}=\right.$ $1(2.535), p=.005)$ and psychological abuse $\left(\chi^{2}=1(11.754)\right.$, $p=.001)$. There were no gender differences in trauma symptoms.

\section{Relationship Between Sequential Trauma, Subsequent Victimisations and Social Support}

The total number of different types of traumas assessed were summed to create a sequential trauma score. A Pearson's correlation found that the more types of trauma a participant had experienced, the greater number of subsequent victimisations recorded by the police at the follow-up $(r=.30, p=.023)$. Higher sequential trauma scores were also significantly associated with lower reported social support $(r=-.48, p<.001)$. Higher sequential trauma scores were significantly related to higher trauma symptomology (intrusion $r=.29, p=.028$ ); hyperarousal ( $r$ $=.37, p=.006)$; total trauma $(r=.33, p=.014)$, and avoidance approached significance $(r=.24, p=.056)$.

To explore the predictors of subsequent victimisation, a three stage hierarchical multiple regression was conducted with number of subsequent victimisations as the criterion variable (see Table 2). At stage one participant gender (male $=0$ female $=1$ ) was entered, at stage two the type of index crime recorded at phase 1 , whether this index crime was domestic abuse where entered along with whether the participant had a history of domestic abuse victimisation were entered. At stage three, the sequential trauma score and the trauma symptoms total score were entered.

The hierarchical multiple regression revealed that at stage one, gender did not significantly contribute to the regression model, $F(1,43)=3.30, p=.076$, but accounted for $7.1 \%$ of the variation in number of subsequent victimisations. Introducing the crime variables at stage two did not explain significant additional variance, $F(4,40)=0.20, p=.896$. Finally, when all six independent variables were added at stage three of the regression model, gender became a significant predictor, the final two predictors, sequential trauma and trauma symptomology, were also significant predictors of number of subsequent victimisations explaining an additional $23.92 \%$ with this change in $R^{2}$ being significant, $F(6,38)=6.721, p=.003$. Together, the six independent variables accounted for $32.4 \%$ of the variance in the number of subsequent victimisations (see Table 2).

\section{Exploring the Timing of First Trauma}

Participants were categorised into three groups based on their reported traumatic experiences exposure. These groups were no previous trauma, first trauma in childhood and first trauma in adulthood. These groups did not differ in the number of subsequent victimisations, $F(2,42)=1.53, p$ $=.228$ or whether they had a history of domestic abuse $\left(\chi^{2}=\right.$ $2(1.364), p=.506)$. Women were significantly more likely than men to report experiencing at least one of their traumatic experiences during childhood $\left(\chi^{2}=2(10.873), p=\right.$ $.004)$.

\section{Comparing Victims' Psychological and Psychosocial Factors}

Throughout the data there was a trend in which those who experienced their first trauma in childhood used less effective coping than both no trauma and adult trauma groups. Of the types of coping behaviours, only religion (which relates to the use of religion to cope) was significantly different $F(2,40)=48.99, p=.004$, with post hoc analysis finding that those who experienced childhood trauma were significantly lower than those who experienced adult $(p=.047)$ or no trauma $(p=.004)$. Comparing the groups on their personality traits there were two significant effects: conscientiousness $F(2,40)=72.03, p=.026$; and

Table 2. Summary of hierarchical regression analysis for variables predicting subsequent victimisations $(N=44)$.

\begin{tabular}{|c|c|c|c|c|c|c|c|c|c|}
\hline \multirow[b]{2}{*}{ Variable } & \multicolumn{3}{|c|}{ Model 1} & \multicolumn{3}{|c|}{ Model 2} & \multicolumn{3}{|c|}{ Model 3} \\
\hline & $\boldsymbol{B}$ & $S E B$ & $\beta$ & $\boldsymbol{B}$ & $S E B$ & $\beta$ & $B$ & $S E B$ & $\beta$ \\
\hline Type of crime & & & & -0.12 & 0.02 & -.09 & -0.01 & 0.02 & .04 \\
\hline Current crime IPV & & & & 0.06 & 0.31 & .03 & 0.06 & 0.28 & .03 \\
\hline Trauma variety & & & & & & & 0.45 & 0.23 & $.35^{*}$ \\
\hline Symptomology & & & & & & & 0.01 & 0.00 & $.32 * *$ \\
\hline $\begin{array}{l}R^{2} \\
\text { F for change in } R^{2}\end{array}$ & \multicolumn{3}{|c|}{$\begin{array}{c}.07 \\
3.30\end{array}$} & \multicolumn{3}{|c|}{$\begin{array}{c}.09 \\
0.20\end{array}$} & \multicolumn{3}{|c|}{$\begin{array}{c}.32 * \\
6.72 * * *\end{array}$} \\
\hline
\end{tabular}

Note. Gender dummy coded male $=0$, female $=1$

$* p<.05 * * p<.01 * * * p<.005$ 
emotional stability, $F(2,40)=77.56, p=.035$. Post hoc analysis found that individuals with historical childhood trauma were significantly less conscientious than those with no trauma $(p=.033)$. Post hoc analysis found that those with childhood trauma were significantly lower on emotional stability than no trauma $(p=.035)$. Analysis of trauma symptomology found that there were significant differences in hyperarousal, $F(2,40)=6.012, p=.005$ and overall trauma symptomology, $F(2,40)=3.472, p=.040$ between the three groups. Post hoc analysis found that the childhood trauma group were significantly higher on hyperarousal than no trauma ( $p=.006)$ and higher on overall trauma symptomology than the no trauma group $(p=.041)$ (see Table 3).

\section{Trauma Qualitative Analysis}

There were three broad themes in the comments participants made at their time two interview in response to the question "how are you feeling now?" These were: Theme one continuing negative impact, theme two no change and

Table 3. Mean (and standard deviations) of self-reported social support experiences, participants' coping behaviours, resilience and trauma symptomology by trauma exposure type.

\begin{tabular}{|c|c|c|c|}
\hline & \multicolumn{3}{|c|}{ Time of exposure } \\
\hline & None $(n=12)$ & Child $(n=14)$ & Adult $(n=18)$ \\
\hline SS: Receive Emotional & $30.45(7.91)$ & $24.00(9.92)$ & $26.41(8.07)$ \\
\hline SS: Give Emotional & $21.81(2.60)$ & $18.77(7.07)$ & $18.65(3.39)$ \\
\hline SS: Receive Instrumental & $15.91(5.38)$ & $12.46(6.61)$ & $14.82(4.39)$ \\
\hline SS: Give Instrumental & $20.45(3.08)$ & $18.08(5.16)$ & $18.24(4.27)$ \\
\hline SS: Total SS & $88.64(16.94)$ & $73.31(25.33)$ & $78.12(15.90)$ \\
\hline C: Self-distraction & $3.73(1.73)$ & $5.23(2.24)$ & $5.12(1.83)$ \\
\hline C: Active Coping & $4.82(1.66)$ & $5.46(1.66)$ & $4.82(2.04)$ \\
\hline C: Substance Use & $3.27(1.61)$ & $3.38(1.94)$ & $3.29(1.40)$ \\
\hline C: Disengagement & $2.55(.93)$ & $3.46(1.90)$ & $3.06(1.73)$ \\
\hline C: Venting & $3.27(1.16)$ & $3.92(2.02)$ & $3.59(1.62)$ \\
\hline C: Positive Reframing & $4.27(2.00)$ & $4.15(1.91)$ & $4.74(2.04)$ \\
\hline C: Planning & $4.45(2.30)$ & $4.61(1.66)$ & $4.76(2.05)$ \\
\hline C: Humour & $3.27(2.20)$ & $4.69(2.39)$ & $3.65(2.11)$ \\
\hline C: Acceptance & $5.18(2.04)$ & $6.38(1.70)$ & $5.76(2.11$ \\
\hline C: Religion & $4.81(2.92)^{\mathrm{a}}$ & $2.00(.00)^{\mathrm{a}}$ & $2.88(1.90)^{\mathrm{a}}$ \\
\hline C: Self-Blame & $3.55(1.51)$ & $3.62(1.71)$ & $3.35(1.57)$ \\
\hline P: Extraversion & $9.27(1.50)$ & $8.53(2.93)$ & $9.00(1.14)$ \\
\hline P: Agreeableness & $9.81(2.14)$ & $9.54(1.81)$ & $9.29(2.71)$ \\
\hline P: Conscientiousness & $12.73(2.20)^{\mathrm{b}}$ & $9.38(2.76)^{\mathrm{b}}$ & $10.18(3.52)$ \\
\hline P. Emotional Stability & $10.45(3.32)^{\mathrm{c}}$ & $6.85(3.12)^{\mathrm{c}}$ & $8.53(3.26)$ \\
\hline P: Openness & $10.27(1.85)$ & $9.69(3.11)$ & $10.65(2.26)$ \\
\hline R: Resilience & $11.45(2.40)$ & $11.00(2.96)$ & $11.33(2.93)$ \\
\hline TS: Avoidance & $0.94(.90)$ & $1.56(.92)$ & $1.37(.72)$ \\
\hline TS: Intrusion & $.94(1.01)$ & $1.79(1.30)$ & $1.30(1.07)$ \\
\hline TS: Hyperarousal & $0.69(1.10)^{\mathrm{d}}$ & $2.13(1.23)^{\mathrm{d}}$ & $1.20(1.05)^{\mathrm{d}}$ \\
\hline TS: Total & $19.23(20.59)^{\mathrm{e}}$ & $39.86(23.18)^{\mathrm{e}}$ & $28.56(17.81)^{\mathrm{e}}$ \\
\hline
\end{tabular}

Note. $\mathrm{SS}=$ social support, $\mathrm{C}=$ coping, $\mathrm{P}=$ personality traits, $\mathrm{R}=$ resilience and $\mathrm{TS}=$ trauma symptoms.

${ }^{\text {abcde }}$ Child significantly lower. 
Table 4. Participant characteristics, current and prior victimisation history and time since first and second interviews.

\begin{tabular}{|c|c|c|c|c|c|c|}
\hline PPT No. & Gender & Age & Index victimisation & $\begin{array}{l}\text { Recorded victimisation } \\
\text { history }\end{array}$ & $\begin{array}{c}\text { Days since index } \\
\text { victimisation and first } \\
\text { interview }\end{array}$ & $\begin{array}{l}\text { Days since index } \\
\text { victimisation and } \\
\text { second interview }\end{array}$ \\
\hline 24 & M & 27 & Assault with Injury & None recorded & 298 & 474 \\
\hline 25 & M & 34 & Public fear, alarm or distress & $\begin{array}{c}\text { Racial incidents, criminal } \\
\text { damage }\end{array}$ & 242 & 452 \\
\hline 26 & M & 47 & Public fear, alarm or distress & Racial incidents, theft & 224 & 454 \\
\hline 32 & $\mathrm{~F}$ & 34 & Harassment (DV) & $\begin{array}{l}\text { Actual bodily harm, theft, } \\
\text { criminal damage }\end{array}$ & 225 & 463 \\
\hline 38 & M & 43 & Wounding & Wounding, criminal damage & 243 & 453 \\
\hline 55 & M & 20 & Robbery of personal property & None recorded & 316 & 506 \\
\hline 59 & M & 55 & Assault with Injury & $\begin{array}{l}\text { Theft, wounding, criminal } \\
\text { damage, assault }\end{array}$ & 304 & 505 \\
\hline 60 & $\mathrm{~F}$ & 32 & Assault without Injury (DV) & Domestic violence & 202 & 403 \\
\hline 65 & $\mathrm{~F}$ & 41 & Domestic violence & Domestic violence & Unknown* & Unknown* \\
\hline 69 & M & 67 & Assault with Injury & None recorded & 336 & 511 \\
\hline 71 & M & 19 & Harassment (DV) & None recorded & 232 & 430 \\
\hline 104 & $\mathrm{~F}$ & 36 & Assault without Injury & None recorded & 361 & 515 \\
\hline
\end{tabular}

Note. *denotes where information was not recorded on the database.

theme three improvement (see Table 4).

\section{Continuing Negative Impact}

Individuals respond to traumatic events in different ways. It is suggested that a number of coping trajectories exist following a stressor, all of which initially involve some degree of negative emotional and psychological adversity (Carver, 1998). A number of participants reported at phase 2 how their victimisation negatively impacted on their daily functioning. The following participant described how she was plagued with intrusive thoughts and how her perceptions of the world had changed since the event:

P54: female, victim of assault, earliest trauma in childhood (attack on family member, emotional/psychological mistreatment)

I do wake up and that with it [the victimisation] now, I used to for a long time...I had nightmares and waking up, I couldn't settle. I still have the door locked during the day. It does change your opinion of people...I would look for the best in them. I wouldn't do it anymore....It made me very nervous and erm...I suffer from depression anyway so that made it a lot worse and it was it took a long time to sort of...get brave enough even to go out and...you know sort of face it. I knew they [victim services] were there, but you sort of don't think about it at the time because you're in such a trauma that you're not...functioning really, you're not thinking about that sort of stuff.

Her comments reflect commonly reported traits of posttraumatic stress, such as intrusive thoughts, avoidance, guardedness and anxiety (American Psychological Association, 2013). For some participants, their victimisation had altered their daily routines in the sense they would avoid environments and situations associated with the prior trauma:

P38: male, victim of wounding, earliest trauma in childhood (severely attacked, man-made disaster)

I don't go into town anymore...I've moved now so I have to get a taxi. But I wouldn't walk, I wouldn't walk home anymore... I wouldn't feel safe in err... Preston town centre like I used to do.

P105: male, victim of assault, earliest trauma in childhood (sexual trauma, man-made disaster, witnessed suicide/death/injury of friend/family member, severely attacked)

And then that [the assault] happened and it was basically just like "I can't be arsed I don't wanna go out anymore - I don't want something to happen", and when I do go out something usually happens, so it's like - don't go out now.

P55: male, victim of robbery, no prior trauma history 
I think it's affected me as...it's stopped me from training after dark and stuff...I have to change all my schedules around it. I'm a lot more cautious now.

Trauma does not necessarily refer to adversity arising from a particular event or situation. Trauma can be embedded in societal attitudes, behaviours and systems that in turn influence both the stressor and the outcome (Goldsmith, Martin \& Smith, 2014). This notion of 'systemic trauma' finds that the environment can sustain the effects of trauma; in a criminal justice setting, this may refer to the police and judicial processes that are known to have retraumatising effects on the victim (Campbell, Wasco, Ahrens, Sefl \& Barnes, 2001). The following participants' comments illustrate how their experience of the criminal justice system can often sustain the effects of trauma:

P65: female, victim of domestic violence, earliest trauma in childhood (accident, man-made disaster, sexual trauma, emotional/psychological mistreatment)

It's deeply personal, it's deeply traumatic, you're building yourself up to pour your heart out to somebody, you've got a serious problem or considering you've got a serious problem and you're looking for answers in somebody. Once you get into the system you're revictimised over and over and over again. And it's not what the perpetrator does to you, it's what the system does to you that is the real...erm kind of crushing point into your life.

P26: male, victim of public fear, alarm or distress, earliest trauma in adulthood (accident)

When things happen they themselves are stressful because obviously they cause stress and anxiety. But then going through the process - the due process - it extends that stress.

\section{No Change}

It is suggested that some individuals are initially negatively affected by a stressor, but that over time, return to a state of pre-trauma functioning, known as recovery or resilience (Carver, 1998). This is the most common pathway for trauma survivors (Bonnano, 2005). A number of participants related that they had returned to a psychological state that existed prior to the attack:

P32: female, victim of harassment, earliest trauma in childhood (sexual trauma)

Initially I was isolated really from the friends and family because they caused a lot of trouble and its took a long time really to repair that.

P52: female, victim of domestic violence, earliest trauma in childhood (witnessed suicide/death/injury of friend/family member, severely attacked, emotional/psychological mistreatment)

On top of the world...[laughs] compared to last time [first interview]- different, completely different... erm... and that is with help from domestic violence unit that's - that is solely down to them [victim service].

Interestingly, some participants reported that their victimisation had not affected them in any significant way. There is no extant literature on individuals who are seemingly asymptomatic, although this in itself may be an avoidance or emotional numbing strategy (Olafson \& Boat, 2000).

P71: male, victim of domestic violence, earliest trauma in childhood (witnessed severe attack on friend/family member)

I've always been like this - sort of laid back and everything. I've been more of a realist than anything, realising things are gonna happen then and well look it's happened, get over it sort of thing. So no, [the experience has] not really changed me really.

P25: male, victim of public fear, alarm or distress, no prior trauma history

I'd say I'm fairly mentally strong to carry on with life, let's say. Obviously I'm not happy with what's happened, but it's not going to affect my day to day life, let's say. So I don't really need to go to any other services, if that makes sense..... I just feel I can deal with the police and that's the end of the matter effectively. I carry on with my life as normal. I won't let it affect me in any way and I'll carry on doing the things that I do.

\section{Improvement}

Another coping pathway identified by Carver (1998) refers to an increased capacity to deal with further problems. In this manner the victimisation, although certainly traumatising, has allowed the person to achieve a higher state of functioning than that what had existed previously. This fairly recent phenomenon is known as 'post-traumatic growth', which refers to the human ability to positively thrive after adversity (Calhoun \& Tedeschi, 2014). However, positive change can co-exist alongside trauma symptoms and practical and psychological difficulties as the individual continues to process the trauma (Shakespeare-Finch \& LurieBeck, 2014). The following comment characterises both sides of growth following victimisation:

P59: male, victim of assault, earliest trauma in childhood severely attacked, witnessed suicide/death/injury of friend/family member)

It has changed for the better because I've moved from there...I can sleep now, I can wake up, jump in the shower...I don't know if it's psychological...in your mind because I know nobody's knocking at my door. Nobody knows where I live, I don't even tell my best friends where I live because I don't... want any problems like that again...I just want to be left...I'm in tired in life now as it is, it were sending me suicidal actually..I don't even think down that road now.

\section{DISCUSSION}

The current study sought to explore the relationship between childhood and adulthood traumatic experiences, violent crime victimisation and revictimisation suffered throughout life. These events were investigated in relation to current psychological and psychosocial functioning. This study extends knowledge that is currently lacking in the literature on the roles of prior traumatic experiences in risk of subsequent victimisation and psychological functioning. It highlights the importance of prior traumatic experiences in the etiology criminal victimisation and psychological 
wellbeing. In addition, the timing of the first traumatic incident was found to influence psychological functioning which suggests earlier trauma exposure may be an additional risk.

Research has found that women who have experienced multiple episodes of violence are at greater risk of experiencing negative psychosocial outcomes such as PTSD symptoms, poorer adjustment, lifestyle instability, sexual dysfunction, depression, and suicide attempts (Arata, 1999; Banyard, Wiliams \& Siegel, 2001; Ellis, Atkeson \& Calhoun, 1981; Maker, Kemmelmeier \& Peterson, 2001; Miller, Moeller, Kaufman, Divasto, Pathak \& Christy, 1978; Miner, Flitter \& Robinson, 2006; Nishith, Mechanic \& Resick, 2000). There is less research on male victims however. In the current sample, there were few genderdifferences in the types of trauma that men and women were exposed to. Consistent with previous research, men reported more natural disasters and women reported more sexual and psychological trauma (Goldberg \& Freyd, 2006). Women did report experiencing more traumas in childhood than men however. Studies have examined the relationship between gender and subsequent victimisation as a traumatic experience with mixed findings. In their meta-analysis, Brewin et al. (2000) established weak to modest effects for female gender and development of trauma symptoms. These findings supported earlier research conducted by Kessler, Sonnega, Bromet, Hughes and Nelson (1995), whose general population study found that twice as many females as males develop PTSD (10\% vs 5\%), even though males reported more traumatic experiences than females (60\% vs. $51 \%)$. In the current study, there were no gender differences in trauma symptomology, although being male was associated with higher rates of subsequent victimisation. This broadly supports previous research. Lowe et al. (under review) found that when all crime types are considered men in their sample were more likely to be repeatedly victimised than women. $40.7 \%$ of the sample reported significant levels of current distress above Creamer, Bell and Failla's (2003) cut-off for PTSD and as this was reported at phase one interviews which were undertaken at least six months post index victimisation, this points to chronic negative impacts. This suggests that many or even most of the sample should be referred for assessment and potential intervention such as trauma-focused cognitive behavioural therapy/exposure therapy or eye movement desensitisation and reprocessing. Even at the second interview (phase two), which occurred at least one year after the index victimisation, the majority of participants were still experiencing significant symptomology.

The sequential trauma experienced and higher trauma symptomology were associated with higher subsequent police recorded victimisations and explained approximately a third of the variance. This suggests the need for police and support agencies to assess prior trauma exposure when assessing risk of revictimisation (Kelly et al., 2010). This is consistent with the findings of Kira and colleagues who argue that we should consider a 'trauma profile', rather than a single traumatic event in isolation (Kira, Aboumediene, Ashby, Odenat, Mohanesh \& Alamia, 2013). This is consistent with research on women that has found women who experienced multiple episodes of violence were at greater risk of experiencing negative psychosocial outcomes such as PTSD symptoms, poorer adjustment, lifestyle instability, sexual dysfunction, depression, and suicide attempts (Arata, 1999; Banyard et al., 2001; Ellis et al., 1981; Maker et al., 2001; Miller et al., 1978; Miner, et al., 2006; Nishith et al., 2000).

This study found that exposure to one or more traumatic experiences during childhood resulted in higher trauma symptomology and emotional instability than exposure to no trauma prior to the index victimisation. Indeed, those who experienced trauma in childhood exceeded the cut-off score of thirty three (Creamer et al., 2003) for full clinical PTSD assessment. This is consistent with models of trauma that predict that it is the interpretation and impact of a trauma that mediates risk rather than mere exposure (Ehlers \& Clark, 2000). Trauma during childhood is thought to create neurological and emotional vulnerability to subsequent traumatic events (Blair et al., 2006), leaving the victim more psychologically harmed and vulnerable to further trauma than others who have not experienced this (Arata, 2000; Desai, Arias, Thompson \& Basile, 2002; Doll, Koenig \& Purcell, 2004; Iverson, Kester \& Resick, 2011; Widom, Czaja \& Dutton, 2008). Indeed, where violent assault follows previous trauma individuals experience retraumatisation where "one's reaction to a traumatic exposure is coloured, intensified, amplified, or shaped by one's reactions and adaptational styles to previous traumatic experiences" (Danieli, 2010, p. 195). Future research should seek to explore how reactions to preceding trauma (including childhood trauma) have influenced current reactions, rather than exposure alone, as such research would allow the function of current trauma symptomology to be understood in terms of the individual's learning history (Bonow \& Follette, 2012).

Those who have neurotic personality traits have been found to be more likely to develop trauma symptoms (Breslau, Peterson \& Schultz, 2008) and support was found in the current study also, with emotional instability (a core feature of neuroticism) being related to symptoms. This finding is not surprising as the core features of neuroticism include a pervasive sensitivity to negative cues in the environment (McCrae \& Costa, 1991; Costa \& McCrae, 1992) such as violence threat. In addition, individuals high on neuroticism are predisposed to attend to novel situational cues (Wallace \& Newman, 1997, 1998), which they tend to evaluate in terms of their personal relevance, and are particularly sensitive to punishment cues (Pickering \& Gray, 2001) such as those that remind them of their previous experience of negative social situations (Bolger \& Schilling, 1991; Bolger \& Zuckerman, 1995). Finally, individuals high in neuroticism are more prone to evaluate situations as threatening than those lower on this trait (Schneider, 2004). All these features help explain why neuroticism/emotional instability would be a risk factor for trauma symptomology. Interestingly, this also fits with the post-traumatic growth literature; neuroticism is negatively associated with posttraumatic growth (Tedeschi \& Calhoun, 2004), so it also follows they may evaluate situations more severely. 
Trauma research would suggest that it is development of trauma symptomology that is more predictive of subsequent trauma (Orcutt, Erickson \& Wolfe, 2002; Risser, HetzelRiggin, Thomsen \& McCanne, 2006) and criminal victimisation (Arata, 2000; Messman-Moore \& Long., 2000) than exposure alone. The current study supports the latter point as both the range of different traumas experienced and the level of trauma symptomology significantly predicted subsequent criminal victimisation. Of the trauma symptomology, only hyperarousal symptoms were significantly associated with subsequent victimisations which is consistent with research conducted with veterans (Risser et al., 2006). Hyperarousal may increase vulnerability to repeat victimisation via several different but related pathways (Zayfert, 2012), but a promising line of research suggests that self-reported hyperarousal may not map directly onto physiological responses. McTeague, Laplante, Cuthbert, Shumen and Bradley (2010) found evidence that those exposed to multiple prior traumas may report hyperarousal but may show hypo-physiological responses compared to victims of single traumas. Future research should explore both explicit and implicit arousal in trauma-exposed and healthy individuals.

The main limitation of the current study is the small sample size, which will have resulted in a lack of statistical power and hence increase the risk of a type II error. The findings should therefore be treated with caution until future studies are able to replicate these findings with a larger sample size. Despite the lack of statistical power in this study, the findings do point to the strong effect of prior trauma, trauma symptomology and age of first trauma in understanding repeat victimisation risk. Secondly, this study relied on participant recall of past trauma exposure and so may lack accuracy. Retrospective self-reports of trauma history are likely to under represent exposures where the participant disassociates. As the victims were self-selecting (i.e. they responded to requests and attended interviews) there is potential for bias. If more symptomatic victims agreed to participate in studies, compared with those who are less affected by psychological sequelae, this would result in an overestimation of post-traumatic stress. However, refusal to participate in studies is linked closely to explicit concerns about not wanting to revisit the trauma experience. It is therefore also possible that this study underestimates the prevalence of post-traumatic stress because the most avoidant victims do not participate. Those participants who cope via the use of avoidance may also be under-represented in the current sample (particularly at time two interviews) as these individuals are motivated to avoid thinking or discussing the trauma event. Thirdly, dissociation was not assessed. Dissociation can lead individuals into situations of high risk of revictimisation, as they are less likely to detect violations of social contracts and unsafe situations (DePrince, 2005; Hulette et al., 2011). Finally, this study did not use clinical assessment of participant functioning but instead relied on self-reported symptoms which may have resulted in under or over reporting of symptoms. The IES is one of the most widely used assessment tools used by clinicians (Elhai, Gray, Kashdan \& Franklin, 2005) and although it is possible to fabricate scores on the IES (McGuire, 2002), the study participants were not offered any incentive to do so. Additionally, subjective assessments using the IES appear to correspond to clinical judgment (Sundin \& Horowitz, 2002), and have been used to validate clinician assessment (Diehle, de Roos, Boer \& Lindauer, 2013).

\section{Recommendations}

The following recommendations for service providers are made based on the findings detailed above.

- Adults who have been victims of violent crime may experience post-traumatic stress symptoms and so should be routinely screened and alerted to common reactions to such victimisation, as well as some guidance on normal versus problematic symptom severity and/or duration. Victims of violent crime should be evaluated as soon as possible for past traumatic exposure, and this should include exploration of first exposure timing.

- Trauma symptomology was common in this sample and it is therefore recommended that victims are given a checklist of potential symptoms that are normalised as part of a criminal victimisation. This checklist should be provided both at initial contact and again at regular intervals up to 18 months. Points of contact and help should also be provided at these times.

- If symptoms persist for more than four weeks or are severe, assessment and/or treatment should be arranged. Therefore victim services need to engage with violent crime victims not just initially but also at regular intervals for up to 12 months.

- Trauma-focused interventions should be provided and should be resourced so that they are accessible if and when needed by violent crime victims. Psychological treatments that have been found to be helpful include trauma-focused cognitive behavioural therapy/exposure therapy (group and individual) and eye movement desensitisation and reprocessing. Stress management does not appear to have a strong evidence base and other therapies such as supportive therapy, non-directive counselling, psychodynamic therapy and hypnotherapy may actually be harmful and so should be avoided (Bisson, Roberts, Andrew, Cooper \& Lewis, 2013).

\section{Recommendations for Law Enforcement}

- Those with a history of previous victimisation are at elevated risk of repeat victimisation and should therefore be considered high risk victims, regardless of crime type.

- Current practice of evaluating female domestic violence risk needs to be adapted to include assessment of all violent crime victims' risk.

- Trauma symptomology may interfere with a victim's ability to engage with the criminal justice system. For example, hyperarousal may make the victim appear to be an unsympathetic witness, intrusive thoughts may 
lead to the victim being overwhelmed by the simplest of tasks; avoidance may result in the victim failing to recall important aspects of the event or coping by complete disengagement. The latter is particularly worth noting given that some people may present as asymptomatic, so professionals might interpret this as the victim not being affected by the trauma. Therefore, management and symptom alleviation should be a criminal justice priority.

\section{CONFLICT OF INTEREST}

The authors confirm that this article content has no conflict of interest.

\section{ACKNOWLEDGEMENTS}

This work was supported by the European Union under Grant JUST/2011/JPEN/AG/2925. The authors would like to thank Lancashire Constabulary and Victim Support (Preston) for their continued support of this work.

\section{REFERENCES}

Aldao, A., Nolen-Hoeksema, S., \& Schweizer, S. (2010). Emotion regulation strategies and psychopathology: A meta analysis. Clinical Psychology Review, 30, 217-237.

American Psychiatric Association (2013). Diagnostic and Statistical Manual of Mental Disorders $\left(5^{\text {th }}\right.$ ed.) Washington, DC: American Psychiatric Association.

Arata, C. M. (1999). Coping with rape: The roles of prior sexual abuse and attributions of blame. Journal of Interpersonal Violence, 14(1), 6278.

Arata, C. M. (2000). From child victim to adult victim: A model for predicting sexual revictimisation. Child Maltreatment, 5(1), 28-38.

Banyard, V. L., Williams, L. M. \& Siegel, J. A. (2001). The long-term mental health consequences of child sexual abuse: An exploratory study of the impact of multiple traumas in a sample of women. Journal of Traumatic Stress, 14(4), 697-715.

Batten, S. V., Follette, V. M., \& Aban, I. B. (2002). Experiential avoidance and high-risk sexual behavior in survivors of child sexual abuse. Journal of Child Sexual Abuse, 10(2), 101-120.

Bisson, J. I., Roberts, N. P., Andrew, M., Cooper, R. \& Lewis, C. (2013). Psychological therapies for chronic post-traumatic stress disorder (PTSD) in adults. The Cochrane Library, 12, 1-141.

Bolger, N. \& Schilling, E. A. (1991). Personality and problems of everyday life: The role of neuroticism in exposure and reactivity to daily stressors. Journal of Personality, 59, 356-386.

Bolger, N. \& Zuckerman, A. (1995). A framework for studying personality in the stress process. Journal of Personality and Social Psychology, $69,890-902$

Bonnano, G. A. (2005). Resilience in the face of potential trauma. Current Directions in Psychological Science, 14(3), 135-138.

Bonow, J. T. \& Follette, C. (2012). A functional analytic conceptualization of retraumatization: Implications for clinical assessment. In M. P. Duckworth \& V. M. Follette (Eds.), Retraumatisation: Assessment, Treatment and Prevention (pp. 129-162). New York: Routledge.

Bradley, S. J. (2000). Affect Regulation and the Development of Psychopathology. New York: Guilford.

Braun, V. \& Clarke, V. (2006). Using thematic analysis in psychology. Qualitative Research in Psychology, 3(2), 77-101.

Breslau N., Peterson, E. L., \& Shultz, L. R. (2008). A second look at prior trauma and the post-traumatic stress disorder effects of subsequent trauma. Archives of General Psychiatry, 65, 431-437.

Brewin, C. R., Andrews, B. \& Valentine, J. D. (2000). Meta-analysis of risk factors for post-traumatic disorder in trauma exposed adults. Journal of Consulting and Clinical Psychology, 68(5), 748-766.

Cabrera, O. A., Hoge, C. W., Bliese, P. D., Castro, C. A., \& Messer, S. C. (2007). Childhood adversity and combat as predictors of depression and post-traumatic stress in deployed troops. American Journal of Preventative Medicine, 33(2), 77-82.
Calhoun, L. G. \& Tedeschi, R. G. (2014). Handbook of post-traumatic growth: Research and practice ( $2^{\text {nd }}$ ed.). New York, NY: Psychology Press.

Campbell, R., Wasco, S. M., Ahrens, C. E., Sefl, T. \& Barnes, H. E. (2001). Preventing the "second rape": Rape survivors' experiences with community service providers. Journal of Interpersonal Violence, 16(12), 1239-1259.

Carver, C. S. (1998). Resilience and thriving: Issues, models and linkages. Journal of Social Issues, 54(2), 245-266.

Carver, C. S. (1997). You want to measure coping but your protocol's too long: Consider the Brief COPE. International Journal of Behavioural Medicine, 4(1), 92-100.

Creamer, M., Bell, R. \& Failla, S. (2003). Psychometric properties of the Impact of Event Scale-Revised. Behaviour Research and Therapy, $41,1489-1496$.

Cohen, L. E., \& Felson, M. (1979). Social change and crime rates: A routine activities approach. American Sociological Review, 44, 588-608.

Costa, P. T. \& McCrae, R. R. (1992). The Revised NEO Personality Inventory (NEO PI-R) Professional Manual. Odessa, FL: Psychological Assessment Resources.

Danieli, Y. (2010). Fundamentals of working with (re)traumatised populations. In G. H. Brenner, D. H. Bush \& J. Moses (Eds.), Creating Spiritual and Psychological Resilience: Integrating Care in Disaster Relief Work. (pp. 195-210). New York: Routledge/Taylor \& Francis.

Davidson, G., Devaney, J., \& Spratt, T. (2010). The impact of adversity in childhood on outcomes in adulthood. Journal of Social Work, 10(4), 369-390.

Davis, R. C., Maxwell, C. D. \& Taylor, B. (2006). Preventing repeat incidents of family violence: Analysis of data from three field experiments. Journal of Experimental Criminology, 2(2), 183-210.

DePrince, A. P. (2005). Social cognition and revictimisation risk. Journal of Trauma \& Dissociation, 6(1), 125-141.

Desai, S., Arias, I., Thompson, M. P., \& Basile, K. C. (2002). Childhood victimisation and subsequent adult revictimisation assessed in a nationally representative sample of women and men. Violence and Victims, 17(6), 639-653.

Diehle, J., de Roos, C., Boer, F., \& Lindauer, R. L. (2013). A cross-cultural validation of the Clinician Administered PTSD Scale for Children and Adolescents in a Dutch population. European Journal of Psychotraumatology, 4, 896.

Doll, L. S., Koenig, L. J. \& Purcell, D.W. (2004). Child sexual abuse and adult sexual risk: Where are we now? In L.S. Doll, S.O. O'Leary, L.J. Koenig \& W. Pequegnat (Eds.), From Child Sexual Abuse to Adult Sexual Risk. (pp. 3-10). Washington, DC: American Psychological Association.

Dumais, A., De Benedictis, L. D., Joyal, C., Allaire, J. F., Lessage, A. \& Côte, G. (2013). Profiles and mental health correlates of alcohol and illicit drug use in the Canadian population: An exploration of the J-curve hypothesis. Canadian Journal of Psychiatry, 58(6), 344-352.

Dutton, D. G. (2002). The neurobiology of abandonment homicide. Aggression and Violent Behavior, 7, 407-421.

Dutton, D. G., Green, B. L., Kaltman, S. I., Roesch, D. M., Zeffiro, T. A. \& Krause, E. D. (2006). Intimate partner violence, PTSD, and adverse health outcomes. Journal of Interpersonal Violence, 21(7), 955968.

Dyb, G., Jensen, T. K., Nygaard, E., Ekeberg, O., Diseth, T. H., WentzelLarsen, T. \& Thoresen, S. (2014). Post-traumatic stress reactions in survivors of the 2011 massacre on Utøya Island, Norway. British Journal of Psychiatry, 204, 361-367.

Ehlers, A. \& Clark, D. M. (2000). A cognitive model of post-traumatic stress disorder. Behaviour, Research and Therapy, 38(4), 319-345.

Elhai, J. D., Gray, M. J., Kashdan, T. B., \& Franklin, C. L. (2005). Which Instruments Are Most Commonly Used to Assess Traumatic Event Exposure and Posttraumatic Effects?: A Survey of Traumatic Stress Professionals. Journal of Traumatic Stress, 18(5), 541-545. doi: $10.1002 /$ jts. 20062

Ellis, E. M., Atkeson, B. M. \& Calhoun, K. S. (1981). An assessment of the long-term reaction to rape. Journal of Abnormal Psychology, 90 263-266.

Evans, S. E., Steel, A. L., Watkins, L. \& DiLillo, D. (2014). Childhood exposure to family violence and adult trauma symptoms: The importance of social support from a spouse. Psychological Trauma: Theory, Research, Practice and Policy, 6(5), 527-536. 
Faergemann, C., Lauritsen, J., Brink, O., \& Mortensen, P. B. (2010). Do repeat victims of interpersonal violence have different demographic and socioeconomic characters from non-repeat victims of interpersonal violence and the general population? A populationbased case-control study. Scandinavian Journal of Public Health, 38(5), 524-32.

Farrell, G. (2005) Progress and Prospects in the Prevention of Repeat Victimisation. In: Tilley, N. (ed.) Handbook of Crime Prevention and Community Safety. Cullompton: Willan.

Farrell, G., \& Pease, K. (1993). Once bitten, twice bitten: Repeat victimisation and its implications for crime prevention. Police Research Group, Crime Prevention Unit Paper 46. London; Home Office Police Department.

Farrell, G., Tseloni, A., \& Pease, K. (2005). Repeat victimisation in the ICVS and NCVS. Crime Prevention and Community Safety, 7(3), $7-18$.

Finklehor, D., Turner, H., Hamby, S., \& Ormrod, R. (2011). Polyvictimisation: Children's exposure to multiple types of violence, crime and abuse. Free Inquiry in Creative Sociology, 39(2), 24-34.

Follette, V. M., Polusny, M. A., Bechtle, A. E. \& Naugle, A. E. (1996). Cumulative trauma: The impact of child abuse, sexual abuse, adult sexual assault and spouse abuse. Journal of Traumatic Stress, 9(1), 25-35.

Fortier, M. A., DiLillo, D., Messman-Moore, T. L., Peugh, J., DeNardi, K. A., \& Gaffey, K. J. (2009). Severity of child sexual abuse and revictimisation: The mediating role of coping and trauma symptoms. Psychology of Women Quarterly, 33(3), 308-320.

Goldberg, L. R. \& Freyd, J. J. (2006). Self-reports of potentially traumatic experiences in an adult community sample: Gender differences and test-retest stabilities of the items in a Brief Betrayal-Trauma Survey. Journal of Trauma \& Dissociation, 7(3), 39-63.

Goldsmith, R. E., Martin, C. G. \& Smith, C. P. (2014). Systemic trauma. Journal of Trauma \& Dissociation, 15(2), 117-132.

Gosling, S. D., Rentfrow, P. J. \& Swann Jr., W. B. (2003). A very brief measure of the Big-Five personality domains. Journal of Research in Personality, 37(6), 507-528.

Green, D. L. \& Pomeroy, E. C. (2007). Crime victims: What is the role of social support? Journal of Aggression, Maltreatment and Trauma, 15(2), 97-113.

Halligan, S. L., Michael, T., Clark, D. M. \& Ehlers, A. (2003). Posttraumatic stress disorder following assault: The role of cognitive processing, trauma memory and appraisals. Journal of Consulting and Clinical Psychology, 71(3), 419-431.

Hassel, A., Nordfjærn, T., \& Hagen, N. (2013). Psychological and interpersonal distress among patients with substance use disorders: Are these factors associated with continued drug use and do they change during treatment? Journal of Substance Use, 18(5), 363376.

Hulette, A. C., Kaehler, L. A., \& Freyd, J. J. (2011). Intergenerational associations between trauma and dissociation. Journal of Family Violence, 26(3), 217-225.

Iverson, K. M., Lester, K. M., \& Resick, P. A. (2011). Psychosocial treatments. In D. M. Benedek \& G. H. Wynn (Eds)., Clinical Manual for Management of PTSD (pp. 157-203). Arlington, VA: American Psychiatric Publishing.

John, O. P., \& Gross, J. J. (2004). Healthy and unhealthy emotion regulation: Personality processes, individual differences, and lifespan development. Journal of Personality, 72, 1301-1334.

Kelly, V. G., Merrill, G. S., Shumway, M., Alvidrez, J., \& Boccellari, A. (2010). Outreach, engagement, and practical assistance: Essential aspects of PTSD care for urban victims of violent crime. Trauma, Violence, \& Abuse, 11, $144-156$.

Kessler, R. C., Berglund, P., Demler, O., Merikangas, Jin, R., \& Walters, K. R. (2005). Lifetime prevalence and age-of-onset distributions of DSM-IV disorders in the National Comorbidity Survey replication. Archives of General Psychiatry, 62(6), 593-602.

Kessler, R. C., Sonnega, A., Bromet, E., Hughes, M., \& Nelson, C. B. (1995). Post-traumatic stress disorder in the National Co-morbidity Survey. Archives of General Psychiatry, 52(12), 1048-1060.

Kira, I., A., Aboumediene, S., Ashby, J. S., Odenat, L., Mohanesh, J., \& Alamia, H. (2013). The dynamics of post-traumatic growth across different trauma types in a Palestinian sample. Journal of Loss \& Trauma, 18(2), 120-139.

Layne, C. M., Warren, J. S., Saltzman, W. R., Fulton, J., Steinberg, A. M., \& Pynoos, R. S. (2006). Contextual influences on post-traumatic adjustment: Retraumatization and the roles of distressing reminders, secondary adversities, and revictimisation. In L. A. Schein, H. I. Spitz, G. M. Burlingame \& P. R. Muskin (Eds.), Group Approaches for the Psychological Effects of Terrorist Disasters (pp. 235-286). New York, NY: Haworth.

Lowe, M., Willan, V. J., Graham-Kevan, N., Brooks, M., Karwacka, M., Irving, M., Khan, R., Stokes, R., Robinson, P., \& Bryce, J. (under review). Investigating repeated victimisation in a UK police sample of adult victims of violent crime. Policing \& Society.

Maker, A. H., Kemmelmeier, M., \& Peterson, C. (2001). Child sexual abuse, peer sexual abuse, and sexual assault in adulthood: A multirisk model of revictimisation. Journal of Traumatic Stress, 14(2), 351-368.

McTeague L. M., Lang, P. J., Laplante, M. C., Cuthbert, B. N., Shumen, J. R., \& Bradley, M. M. (2010). Aversive imagery in PTSD: Trauma recurrence, comorbidity, and physiological reactivity. Biological Psychiatry, 67, 346-356.

Meloy, J. R. (1992). Violent attachments. New Jersey: Aronson.

Messman-Moore, T. L., \& Long, P. J. (2000). Child sexual abuse and revictimisation in the form of ASA, adult physical abuse, and adult psychological maltreatment. Journal of Interpersonal Violence, 15, 489-502.

Mezey, G., Bacchus, L., Bewley, S. \& White, S. (2005). Domestic violence, lifetime trauma and psychological health of childbearing women. BJOG, 112(2), 197-204.

McCrae, R. R., \& Costa, P. T. (1991). Adding liebe und arbeit: The full five-factor model and well-being. Personality and Social Psychology Bulletin, 17(2), 227-232.

McGuire, B. E. (2002). Malingered post-traumatic stress symptoms on the Impact of Event Scale. Legal And Criminological Psychology, 7(2), 165-171. doi:10.1348/135532502760274774

Miller, J., Moeller, D., Kaufman, A., Divasto, P., Pathak, D., \& Christy, J. (1978). Recidivism among sex assault victims. American Journal of Psychiatry, 135, 1103-1104.

Miner, M. H., Flitter, J. M. K., \& Robinson, B. E. (2006). Association of sexual revictimisation with sexuality and psychological function. Journal of Interpersonal Violence. 21, 503-524.

Nishith, P., Mechanic, M. B., \& Resick, P. A. (2000). Prior interpersonal trauma: The contribution to current PTSD symptoms in female rape victims. Journal of Abnormal Psychology, 109(1), 20-25.

Orcutt, H. K., Erickson, D. J., \& Wolfe, J. (2002). A prospective analysis of trauma exposure: The mediating role of PTSD symptomatology. Journal of Traumatic Stress, 15(3), 259-266.

Olafson, E., \& Boat, B. W. (2000). Long-term management of the sexually abused child: Considerations and challenges. In R. M. Reece (Ed.), Treatment of Child Abuse: Common Ground for Mental Health, Medical, and Legal Practitioners (pp. 14-35). Baltimore, MD: Johns Hopkins University Press.

Outlaw, M., Ruback, B., \& Britt, C. (2002). Repeat and multiple victimisations: The role of individual and contextual factors. Violence and Victims, 17, 187-204.

Pease, K. (1998). Repeat Victimisation: Taking Stock, Police Research Series, Paper 90. London: Home Office.

Perkins, S., \& Graham-Bermann, S. (2012). Violence exposure and the development of school-related functioning: Mental health, neurocognition and learning. Aggression and Violent Behavior, 17(1), 89-98.

Pickering, A. D., \& Gray, J.A. (2001). Dopamine, appetitive reinforcement, and the neuropsychology of human learning: An individual differences approach. In A. Eliasz \& A. Angleitner (Eds.), Advances in Individual Differences Research (pp. 113-149). Lengerich, Germany: PABST Science Publishers.

Risser, H. J., Hetzel-Riggin, M. D., Thomsen, C. J., \& McCanne, T. R. (2006). PTSD as a mediator of sexual revictimisation: The role of re-experiencing, avoidance and arousal symptoms. Journal of Traumatic Stress, 19(5), 687-698.

Roberton, T., Daffern, M., \& Bucks, R. S. (2012). Emotion regulation and aggression. Aggression and Violent Behavior, 17(1), 72-82.

Sansone, R. A., Leung, J. S., \& Wiederman, J. W. (2012). Five forms of childhood trauma: Relationships with employment in adulthood. Child Abuse \& Neglect, 36, 676-679.

Schneider, T. R. (2004). The role of neuroticism on psychological and physiological stress responses. Journal of Experimental Social Psychology, 40, 795-804.

Shakespeare-Finch, J., \& Obst, P. L. (2011). The development of the 2-Way Social Support Scale: A measure of giving and receiving emotional 
and instrumental support. Journal of Personality Assessment, 93(5), 483-490.

Shakespeare-Finch, J., \& Lurie-Beck, J. (2014). A meta-analytic clarification of the relationship between post-traumatic growth and symptoms of post-traumatic stress disorder. Journal of Anxiety Disorders, 28(2), 223-229.

Stimmel, M., Cruise, K. R., Ford, J. D., \& Weiss, R. A. (2014). Trauma exposure, post-traumatic stress disorder symptomatology, and aggression in male juvenile offenders. Psychological Trauma: Theory, Research, Practice and Policy, 6(2), 184-191.

Sundin, E. C., \& Horowitz, M. J. (2002). Impact of event scale: psychometric properties. British Journal of Psychiatry, 180, 205209.

Tedeschi, R. G., \& Calhoun, L. G. (2004). Post-traumatic growth: Conceptual foundations and empirical evidence. Psychological Inquiry, 15(1), 1-18.

The National Child Traumatic Stress Network. (2015). Effects of Complex Trauma. Retrieved on $23^{\text {rd }}$ January 2015 from http://www.nctsn.org/trauma-types/complex-trauma/effects-ofcomplex-trauma\#q2

Tilley, N., \& Laycock, G. (2002). Working Out What to Do: EvidenceBased Crime Reduction. (Crime Reduction Series Paper 11). London, UK: Home Office.

Unger, J. A. M., \& de Luca, R. V. (2014). The relationship between childhood physical abuse and adult attachment styles. Journal of Family Violence, 29, 223-234.

Vaishnavi, S., Connor, K., \& Davidson, J. R. T. (2007). An abbreviated version of the Connor-Davidson Resilience Scale (CD-RISC), the CD-RISC2: Psychometric properties and applications in psychopharmacological trials. Psychiatry Research, 152(2-3), 293297.

Wallace JF., \& Newman, J. P. (1997). Neuroticism and the attentional mediation dysregulatory psychopathology. Cognitive Therapy \& Research, 21(2), 135-156.
Wallace J., F \& Newman J. P. (1998). Neuroticism and the facilitation of the automatic orienting of attention. Personality and Individual Differences, 24(2), 253-266.

Walsh, K., Danielson, C. K., McCauley, J. L., Saunders, B. E., Kipatrick, D. G., \& Resnick, H. S. (2012). National prevalence of post-traumatic stress disorder among sexually revictimised adolescent, college and adult household-residing women. Archives of General Psychiatry, 69(9), 935-942.

Weiss, D. S., \& Marmar, C. R. (1997). The Impact of Event Scale-Revised. In J. P. Wilson \& T. M. Keane (Eds.), Assessing Psychological Trauma and PTSD: A Practitioner's Handbook (pp. 399-411). New York: Guilford Press.

Weisel, D. L. (2005). Analyzing repeat victimisation. In: The Office of Community Oriented Policing Services (Ed.), Problem-Oriented Guides for Police: Problem-Solving Tool Series (No. 4). Washington, DC: U.S. Department of Justice.

Widom, C., Czaja, S., \& Dutton, M. (2008). Childhood victimisation and lifetime revictimisation. Child Abuse \& Neglect, 32, 785-796.

Winkel, F., W., Blaauw, E., Sheridan, L., \& Baldry, A.C. (2003). Repeat criminal victimisation and vulnerability for coping failure: A prospective examination of a potential risk factor. Psychology, Crime and Law, 9, 87-95.

World Health Organisation (2010). International Statistical Classification of Diseases and Related Health Problems, $10^{\text {th }}$ Revision (ICD-10). Geneva: WHO.

Vaishnavi, S., Connor, K., \& Davidson, J. R. T. (2007). An abbreviated version of the Connor-Davidson Resilience Scale (CD-RISC), the CD-RISC 2: Psychometric properties and applications in psychopharmacological trials. Psychiatry Research, 152(2-3), 293297.

Van der Kolk, B. (2014). The body keeps the Score: Brain, Mind and Body in the Healing of Trauma. NY: Viking.

Zayfert, C. (2012). Cognitive behavioural conceptualisation of traumatization. In M. P. Duckworth \& V. M. Follette (Eds.), Retraumatization - Assessment, Treatment and Prevention (pp. 932). New York, NY: Routledge.

() Graham-Kevan et al.; Licensee Bentham Open.

This is an open access article licensed under the terms of the Creative Commons Attribution Non-Commercial License (http://creativecommons.org/licenses/ by-nc/3.0/) which permits unrestricted, non-commercial use, distribution and reproduction in any medium, provided the work is properly cited. 